\title{
Avaliação de desempenho estrutural de protótipo com paredes construídas com blocos EVA
}

\author{
Structural performance evaluation for prototype walls \\ built with EVA blocks
}

\author{
Aluísio Braz Melo \\ Marçal Rosas Florentino Lima Filho
}

\section{Resumo \\ A}

utilização de resíduos de EVA (Etileno Acetato de Vinila), resultado da produção de sandálias, na construção civil tem sido objetivo de pesquisas nos últimos 10 anos. Sabe-se que tais resíduos têm grande potencial para serem empregados como agregados leves, em substituição aos agregados naturais, na elaboração de compósitos cimentícios alternativos. Este artigo, além do destaque para a evolução dos estudos de aplicação desses compósitos na produção de blocos leves, apresenta uma importante etapa do processo de avaliação de desempenho estrutural do prémoldado proposto. As avaliações de cargas de ocupação e impactos nas paredes do protótipo construído com blocos EVA foram realizadas, através de ensaios (impactos de corpos mole e duro, solicitações transmitidas por fechamentos bruscos de porta e cargas provenientes de peça suspensa) que procuram simular situações acidentais e normais de uso de uma edificação. No processo de construção do protótipo observaram-se facilidades no uso dos blocos EVA, que são importantes na perspectiva da redução de resíduos de construção e demolição. À luz do conhecimento atual, baseando-se nos estudos anteriores e considerandose o bom desempenho do protótipo, verificado nos ensaios realizados, sugere-se 1,2 MPa como parâmetro aceitável de resistência à compressão para o bloco EVA.

Palavras-chave: Bloco EVA. Protótipo. Paredes. Impactos. Cargas. Peça suspensa.

Aluísio Braz Melo Departamento de Arquitetura, Centro de Tecnologia

Universidade Federal da Campus I, Cidade Universitária Joao Pessoa - PB - Brasil

Caixa-Postal 350 CEP 58051-900

Tel.: (83) 3216-7115 E-mail:

aluisiobmelo@hotmail.com

Marçal Rosas Florentino Lima Filho

Centro Universitário João Pessoa

BR $230-\mathrm{Km}$, Água Fria João Pessoa - PB - Brasil CEP 58053-000 E-mail:

marcal_civil@yahoo.com.br

Recebido em 15/07/09 Aceito em 06/11/09

\begin{abstract}
The utilization of EVA (Ethylene Vinyl Acetate) waste, a byproduct from the production of sandals, in construction projects has been the object of research in the last 10 years. It is known that EVA waste has great potential to be used as lightweight aggregate, replacing natural aggregates in the production of alternative cement composites. As well as highlighting the development of research into the application of these composites in the production of light blocks, this study shows an important stage in the process of evaluation of the structural performance of the proposed precast. The evaluation of occupancy loads and impacts on the prototype walls built with EVA blocks was done through tests (impacts of soft and hard materials, repercussions of abrupt closing of doors and loads coming from suspended pieces) in order to simulate accidental and normal situations in building use. In the construction process of the prototype, the EVA blocks proved to be easy to use in ways that are important to help reducing construction and demolition waste. According to the current knowledge, based on previous studies and considering the positive performance of the prototype as shown by the tests, 1.2 MPa is suggested as an acceptable parameter of compressive strength for the EVA block.

Keywords: EVA block. Prototype. Walls. Impacts. Loads. Suspended piece.
\end{abstract}




\section{Introdução}

O avanço tecnológico na sociedade moderna, no mundo cada vez mais urbano, tem sido acompanhado de um processo de crescente agressão ao meio ambiente, tendo em conta basicamente o descontrole na exploração de recursos naturais e a enorme geração de resíduos. A atividade da construção civil tem contribuído nesse processo pelo grande consumo dos recursos naturais, cerca de $15 \%$ a $50 \%$ (JOHN, 2000). No Brasil, a produção de agregados para construção civil, em 2005, foi da ordem de 331 milhões de toneladas, entre pedras britadas $(41 \%)$ e areia (59\%), com crescimento de $4,8 \%$ em relação a 2004, sendo $42 \%$ dessa produção concentrada no Estado de São Paulo. Pelo lado da demanda, verificou-se que $70 \%$ do consumo de brita encontravam-se associado à mistura com cimento Portland, sendo $15 \%$ para os pré-fabricados. O consumo médio de agregados no Brasil está pouco acima de 2 t/hab/ano; no Estado de São Paulo são cerca de 4,5 t/hab/ano, enquanto em regiões metropolitanas como Fortaleza e Salvador não atingem 2 t/hab/ano.

O crescimento das atividades industriais, normalmente associado ao processo de urbanização, tem aumentado a geração de resíduos sólidos, de forma generalizada, em ambientes urbanos já com dificuldades para controlar outros tipos de resíduos sólidos (doméstico, hospitalar, da construção e demolição, etc). Sabe-se que o destino final dos resíduos industriais, assim como seu tratamento inadequado, traz sérios problemas para o meio ambiente, por isso a legislação ambiental tem se tornado mais rigorosa, obrigando os geradores de resíduos a tratá-los de maneira adequada. Esse contexto tem despertado para novas políticas de minimização e reciclagem de resíduos. Nesse processo, as pesquisas com materiais de construção alternativos, com aproveitamento de resíduos industriais, são importantes para avaliar as soluções propostas.

Alguns desses resíduos, como o copolímero de etileno-acetato de vinila (EVA), gerados em grandes quantidades pelas indústrias de calçados, são apenas parcialmente (cerca de 20\%) reaproveitados no próprio processo de produção, devido às limitações de suas características físicas (GARLET, 1998). Durante a fabricação do calçado, geram-se resíduos na forma de retalhos das placas expandidas, usadas para a obtenção dos formatos pretendidos, e resíduos em forma de pó, oriundos do lixamento do calçado na fase de acabamento (Figura 1).

O destino dos resíduos da indústria de calçados, em geral, tem sido alimentar os fornos de indústrias de cimento, embora o material tenha potencialidade de ser reciclado como agregado leve para a produção de compósitos aproveitáveis na construção civil. O grande volume de resíduos (cerca de 200 t/mês em apenas uma das indústrias na Paraíba que tem grande produção, cerca de 132 milhões de sandálias/ano) (BEZERRA, 2002; POLARI FILHO, 2005) gerados no processo industrial do setor calçadista demanda muito espaço para armazenagem, em razão de o material possuir baixa densidade.



(a)



(b)

Figura 1 - Detalhe do resíduo gerado durante o processo de fabricação de calçado (a), em forma de aparas e em pó (b) 
Assim, a problemática dos resíduos das indústrias de calçados tem demandado soluções, especialmente nas regiões onde tais atividades se concentram. No Brasil, sabe-se que a produção de calçados é predominante na região Sul, seguida da região Sudeste. Mais recentemente, com a migração de parte dessa indústria para a região Nordeste, esta última tem também se destacado na produção de calçados, especialmente nos estados do Ceará, Paraíba e Bahia, que apresentam crescimento de produção e devem também ter preocupações com o tratamento de seus resíduos. Portanto, a reciclagem desses resíduos se apresenta como uma alternativa interessante para a incorporação desses materiais em outros produtos. Entre as alternativas nos estudos de pesquisa básica aplicada é interessante destacar a busca por aquela que contempla o incentivo à inovação e à experimentação de novos materiais.

$\mathrm{Na}$ alternativa da reciclagem, a construção civil tem grande potencial para absorver resíduos dos outros setores industriais. Isso se justifica pela grande variedade de matérias-primas e pelo grande número de componentes aplicados no processo da construção civil. John (2000) defende que as pesquisas de reciclagem devem ser desenvolvidas para aplicações que proporcionem melhores desempenhos técnicos, menores impactos ambientais, produtos competitivos e possíveis "nichos" de mercado aos produtos alternativos. É ainda de fundamental importância o desenvolvimento de normas técnicas adequadas ao novo produto.

No caso específico dos resíduos de EVA, estudos demonstram que há boas perspectivas de sua incorporação em materiais/produtos à base de compósitos cimentícios utilizáveis na construção civil. Tais estudos, realizados nos últimos 10 anos, contemplam uma evolução no desenvolvimento de um produto; por exemplo, bloco sem função estrutural que utiliza os resíduos de EVA como agregado leve (BEZERRA, 2002; DE MELO; SILVA, 2007; GARLET, 1998; POLARI FILHO, 2005). Entretanto, deve-se levar em conta que a prática da substituição de agregados naturais (areia e cascalho) por agregados artificiais (resíduos de EVA) ainda há de se valorizar, o que pode ser interessante pela possibilidade de redução nas agressões ao meio ambiente, tendo em vista um destino adequado aos resíduos e uma menor extração de matéria-prima da natureza para atender à demanda por materiais de construção.

\section{Blocos com resíduos EVA: evolução dos estudos}

O estudo desenvolvido por Garlet (1998) é um importante referencial sobre o tema no Brasil, que tratou sobre o aproveitamento de resíduos de EVA na construção civil. De sua ampla pesquisa, destacam-se alguns dados que constituem o ponto de partida da evolução dos estudos aqui abordada.

Segundo Garlet (1998), as aplicações e as vantagens para o uso, na construção civil, de compósitos leves obtidos a partir de agregados de EVA podem ser: enchimento para lajes rebaixadas, isolamento acústico entre pavimentos, isolamento térmico nas lajes de forro, etc. Isso evidencia a grande potencialidade desse resíduo para uso em diversos componentes e sistemas na construção civil, sem função estrutural. Em seu estudo, o resíduo de EVA foi coletado da região do Vale dos Sinos, no Rio Grande do Sul, triturado em um moinho, obtendo-se, assim, o agregado de EVA. Os baixos resultados de resistência à compressão (0,8 MPa) de blocos de vedação $(14 \mathrm{~cm}$ x $19 \mathrm{~cm} \mathrm{x}$ $39 \mathrm{~cm}$ ) produzidos com os compósitos leves a partir da incorporação de resíduos de EVA sugeriram inviabilidade do processo, porém as características positivas identificadas (bom acabamento das superfícies, uniformidade de medidas, peso reduzido e boa resistência ao impacto) encorajaram a continuidade dos estudos para esse pré-moldado. O bom desempenho acústico $(41,5 \mathrm{~dB}(\mathrm{~A}))$ de parede com blocos EVA revestida (reboco), que foi comparado por Garlet (1998) aos apresentados pelas paredes de alvenaria com blocos cerâmicos e concreto, também encorajou a continuidade dos estudos.

A dosagem utilizada por Garlet (1998) na moldagem do bloco de vedação foi 1:5 (em volume), utilizando a proporção de $60 \%$ de EVA e $40 \%$ de areia, obtendo-se resultado de absorção de água igual a $12,4 \%$, superior ao parâmetro de $10 \%$ da MB 3459 (ABNT, 1991), vigente em 1998. Outros resultados que caracterizam essa dosagem de concreto leve foram o baixo módulo de deformação (1.200 MPa), a retração por secagem $(0,051 \%)$ e a massa unitária $(1.275 \mathrm{~kg} / \mathrm{m} 3)$.

A contribuição interessante do trabalho de Garlet (1998) refere-se ao estudo de granulometria do resíduo de EVA, no qual se verificou o efeito de um simplificado tratamento térmico (permanência das partículas de EVA imersas em água a $100^{\circ} \mathrm{C}$, durante $30 \mathrm{~min}$ ) na alteração da densidade do agregado de EVA. Com esse tratamento, ocorre a expulsão dos gases expansivos presentes no agregado de EVA, fazendo com que ocorra uma retração das partículas, deixando-as mais densas e 
com menor absorção de água. Ele também verificou a resistência do agregado de EVA à colonização por fungos pertencentes às espécies Aspergillus fumigatus e Aspergillus niger (são organismos comuns no ar e no solo), através do método da câmara tropical e da placa de Petri. Após um período de 90 dias de observação, confirmou-se que não houve avanços na colonização de fungos. Isso o fez concluir que o resíduo EVA poderá ser empregado na construção civil sem precisar de tratamento fungicida.

Para Garlet (1998), a propriedade marcante dos compósitos avaliados foi a baixa rigidez, comportamento atribuído às propriedades do agregado de EVA (baixo módulo de deformação). Desse modo, concluiu que o grande potencial de aplicação desse compósito é para o isolamento térmico e na produção dos chamados pisos flutuantes, que podem atenuar os ruídos transmitidos em lajes entre os pavimentos de edifícios.

Os estudos desenvolvidos por Bezerra (2002) representam uma nova etapa na busca das condições técnicas para utilizar o resíduo EVA como agregado leve na produção de blocos de vedação, com base em compósitos cimentícios. Bezerra (2002) coletou o resíduo de EVA na região de João Pessoa, na Paraíba, e adotou como seu beneficiamento a trituração em moinho de facas para produzir algumas granulometrias predefinidas, em função do diâmetro máximo da partícula $(4,8 \mathrm{~mm}, 9,5 \mathrm{~mm}$ e $12,5 \mathrm{~mm})$. Também foram feitos testes a partir do tratamento térmico das partículas de EVA, conforme sugerido por Galert (1998). A massa unitária do agregado EVA utilizado variou entre $120 \mathrm{~kg} / \mathrm{m}^{3}$ e $430 \mathrm{~kg} / \mathrm{m}^{3}$.

A incorporação de agregado EVA às misturas, numa faixa entre $40 \%$ e $100 \%$ em relação ao volume total de agregados, realizada por Bezerra (2002), teve como objetivo determinar o teor ideal em função de dois parâmetros: uso de maior quantidade de resíduos EVA e produção de blocos de concreto $(9 \mathrm{~cm}$ x $39 \mathrm{~cm}$ x $19 \mathrm{~cm})$ com propriedades físico-mecânicas (resistência à compressão mínima e absorção de água) compatíveis com a utilização sem função estrutural. Neste estudo, optou-se pelo cimento Portland do tipo CP II Z32, por ser o aglomerante mais utilizado na região. Os blocos foram moldados em laboratório em máquina do tipo vibroprensa (não industrial) e, no processo de produção, passaram por duas etapas de cura: cura inicial (imediatamente após a desmoldagem foram para câmara úmida - UR>95\% e $\mathrm{T}=25^{\circ} \mathrm{C}$ ) e cura final (após as primeiras $24 \mathrm{~h}$, imersão em tanques de cura com água saturada com cal) até as idades de controle ( 7 e 28 dias).
Considerando os materiais utilizados e os procedimentos adotados no estudo experimental desenvolvido por Bezerra (2002), destaca-se que com o traço 1:3 (em volume) foram boas as condições para a fabricação de blocos EVA, obtendo-se resultados variáveis, aos 28 dias de idade, para resistências à compressão $\left(\mathrm{fc}_{28}\right.$ entre 0,2 $\mathrm{MPa}$ e 2,5 MPa), para absorção de água (Abs de $6,2 \%$ até $23,7 \%$ ), para massa unitária (666 $\mathrm{kg} / \mathrm{m}^{3}$ até $1.407 \mathrm{~kg} / \mathrm{m}^{3}$ ) e para massa dos blocos EVA $(2,9 \mathrm{~kg}$ até $6,9 \mathrm{~kg})$. Como esperado, a relação foi direta entre menor resistência à compressão e menor massa unitária. Em geral, considerando todos os resultados obtidos e as variáveis trabalhadas, quando os valores das resistências à compressão dos blocos EVA foram maiores ou iguais a 1,2 $\mathrm{MPa}$, o valor-limite para a propriedade absorção de água (Abs<10\%) sempre foi atendido.

Entre as variações estudadas e levando-se em conta os parâmetros da NBR 7173 (ABNT, 1982), vigente em 2002, para produzir blocos EVA foram indicadas por Bezerra (2002) duas possibilidades com uso de compósito cimentício, com traço 1:3 (em volume) com $70 \%$ de agregado de EVA, variando-se a forma de obtenção dos agregados de EVA:

(a) quando, a partir da trituração do resíduo de EVA, resultou em agregado com Dmáx de 9,5 $\mathrm{mm}$, sendo o material em seguida submetido a tratamento térmico, alterando-se o Dmáx para 6,3 $\mathrm{mm}$, atingiu-se 2,5 $\mathrm{MPa}$ de resistência à compressão e 7\% de absorção de água, produzindo-se blocos EVA com massa de $6,5 \mathrm{~kg}$; e

(b) quando, a partir da trituração do resíduo de EVA, resultou em agregado com Dmáx de 12,5 $\mathrm{mm}$, sendo o material em seguida submetido a tratamento térmico, alterando-se o Dmáx para 9,5 $\mathrm{mm}$, atingiu-se 2,4 MPa de resistência à compressão e 6,2\% de absorção de água, produzindo-se blocos EVA com massa de $5,6 \mathrm{~kg}$.

$\mathrm{O}$ custo adicional com tratamento térmico dado ao agregado EVA, presente nas duas possibilidades, significa um aumento no custo do beneficiamento do agregado, mas se deve considerar a vantagem associada à alteração nas características das partículas do EVA (redução de tamanho e aumento de densidade) e o ganho de resistência à compressão dos blocos EVA. Na segunda possibilidade, essa questão é minorada devido à economia de energia no processo de obtenção do agregado (trabalha-se com maior granulometria inicial do EVA; Dmáx=12,5 mm), pela redução do tempo de trituração do resíduo.

Para John (2000), as melhores alternativas para reciclagem, entre outras questões, são as que usam resíduos que podem ser utilizados sem precisar 
passar por nenhum tratamento ou que passam por pouca preparação (separação, classificação e transformação industrial). Portanto, no estudo de Bezerra (2002), destaca-se aquela possibilidade na qual, para a obtenção do agregado EVA, se evitaram maior tempo de trituração e tratamento térmico, cujos resultados com uso do traço 1:3 com $60 \%$ de EVA (Dmáx $=9,5 \mathrm{~mm}$ ) e $40 \%$ de areia foram fc $28=1,6 \mathrm{MPa}$; Abs $=9 \%$.

Todas as possibilidades aqui destacadas (BEZERRA, 2002) atendem aos limites de absorção de água exigidos na norma para blocos de concreto, vigente em 2002 (MB 3459, 1991). Em relação ao acabamento superficial dos blocos EVA, confirmou-se uma superfície mais rugosa quando se combina uso de misturas com maior teor de EVA e agregados de EVA com Dmáx maior. Os blocos EVA demonstraram ser facilmente cortados com uso de serra elétrica, sem gerar quebras indesejáveis, o que pode ser interessante na redução dos entulhos nas obras de construção de edifícios.

Bezerra (2002) destaca como características favoráveis para o novo bloco proposto, os potenciais ganhos na hipótese de sua aplicação: menor peso próprio da alvenaria; maior produtividade em sua execução, pela leveza do pré-moldado; facilidade de corte dos elementos com menor geração de RCD, etc. Como afirma John (2000), no desenvolvimento de novo produto, deve-se procurar satisfazer às perspectivas dos projetistas e construtores, adequando-se de forma eficaz no processo construtivo e sendo de fácil aplicação. Sob esse aspecto, é também oportuno lembrar que, nos estudos de reciclagem, tem importância o desenvolvimento de normas técnicas adequadas ao novo produto (JOHN, 2000). Portanto, a possibilidade de definição de novos parâmetros baseando-se em estudos deve ser considerada, admitindo-se inclusive uma resistência à compressão mínima mais baixa para o bloco EVA. Nesse sentido, os estudos de Bezerra (2002) sugerem uma interessante correspondência entre as duas importantes propriedades para os blocos EVA: quando a resistência à compressão é maior ou igual a 1,2 $\mathrm{MPa}$, o valor-limite para a absorção de água $(\mathrm{Abs}<10 \%)$ é atendido.

Por isso, entende-se que o estudo de Bezerra (2002), embora tenha sido desenvolvido com base em maiores consumos de cimento Portland (traço 1:3, em volume), encorajou o prosseguimento das pesquisas em avaliações para verificar também outros aspectos no desenvolvimento do produto: segurança, habitabilidade e durabilidade.

Nessa perspectiva, Polari Filho (2005) traz contribuições positivas para o estudo de aproveitamento desse resíduo na produção de blocos leves $(9 \mathrm{~cm}$ x $19 \mathrm{~cm}$ x $39 \mathrm{~cm})$. Apoiado na avaliação de desempenho mecânico não só de blocos EVA isoladamente, mas também de paredes compostas com eles, o autor contribuiu na proposição de novo parâmetro de resistência à compressão mínima (1,2 MPa, com base no estudo de Bezerra (2002)) aceitável para o pré-moldado. Para tanto, os resíduos também foram coletados na região de João Pessoa, com os quais desenvolveu um estudo com os traços 1:3 e 1:5 (em volume), incorporando EVA às misturas. O resíduo de EVA foi coletado diretamente do galpão de uma das indústrias geradoras, já triturado em uma granulometria predefinida (Dmáx $=9,5 \mathrm{~mm}$ ), sendo, em seguida, estocada no Laboratório de Ensaios de Materiais e Estruturas, da Universidade Federal da Paraíba (LABEME/UFPB). A massa unitária do agregado de EVA utilizado foi de $105 \mathrm{~kg} / \mathrm{m} 3$. Inicialmente, foram selecionados três compósitos específicos, com traço 1:3, incorporando $60 \%$, $70 \%$ e $80 \%$ de EVA em relação ao volume total de agregados. Além destes, foi estabelecido um quarto compósito, com traço 1:5, incorporando apenas $60 \%$ de EVA em relação ao volume total de agregados. Para avaliar o desempenho de paredes (1,20 m de largura x 2,60 m de altura), utilizaram-se apenas os blocos produzidos com o traço 1:3. Neste estudo, todos os blocos foram produzidos com uso de cimento Portland do tipo CP II Z32 RS.

Polari Filho (2005) deu maior importância a uma determinação mais precisa do teor ideal de água nas misturas estudadas. Isso foi fundamental na obtenção de maiores valores de resistência à compressão dos blocos produzidos, comparativamente àqueles produzidos por Bezerra (2002). Todas as condições de produção dos blocos EVA (pré-molhagem do agregado de EVA, mistura dos materiais, moldagem em equipamento vibroprensa não industrial e cura dos elementos) foram as mesmas adotadas por Bezerra (2002).

Os resultados alcançados com o traço 1:3 (em volume) para resistência à compressão aos 28 dias dos blocos EVA foram de 1,3 $\mathrm{MPa}, 2,2 \mathrm{MPa}$ e 3,3 $\mathrm{MPa}$, conforme o teor EVA presente nas misturas $80 \%, 70 \%$ e $60 \%$ respectivamente. Todas as paredes ensaiadas tiveram bons resultados de desempenho ante as cargas verticais, atingindo-se uma resistência à compressão máxima de $1,7 \mathrm{MPa}$, quando as paredes foram executadas com os blocos com $60 \%$ de agregado de EVA. A maior eficiência (dada pela relação entre a resistência da parede e a resistência do bloco que a compõe) encontrada foi de 0,8 para as paredes executadas com blocos com $80 \%$ de agregado de EVA, sendo a resistência à compressão média dessas paredes 
de 1,0 MPa (carga de $92 \mathrm{kN} / \mathrm{m}$ ). Percebeu-se ainda, durante o ensaio, que essa parede mantém sua capacidade resistente, chegando a suportar quase o dobro da carga imposta desde o momento do surgimento da primeira fissura.

Com base no estudo de Polari Filho (2005), os resultados demonstraram que é possível atingir resistências à compressão de 1,3 MPa para o bloco EVA (com massa de 5,9 kg), utilizando dosagem 1:5, com $60 \%$ de EVA substituindo agregados naturais (mesmo valor obtido com traço $1: 3$, com $80 \%$ de EVA). Nota-se que o valor de 1,3 MPa é cerca de $60 \%$ maior do que aquele obtido no estudo de Garlet (1998), o que encoraja o prosseguimento das pesquisas, contemplando outras etapas de avaliações dos pré-moldados propostos.

Na sequência dessas avaliações, como uma importante etapa que contribui para estabelecer para o bloco EVA um novo parâmetro de resistência à compressão, apresentam-se estudos de verificação do desempenho de blocos EVA (produzidos com traço 1:5, 60\% de EVA, conforme Polari Filho (2005)) aplicados em alvenarias de uma construção em escala real (protótipo que simula um ambiente de edificação), onde foram simuladas situações acidentais e normais de uso, avaliando-se as seguintes ações em paredes: impactos de corpo mole e de corpo duro, solicitações transmitidas por fechamentos bruscos de porta e cargas provenientes de peças suspensas.

\section{Ensaios em protótipo com alvenarias de bloco EVA}

No estudo desenvolvido construiu-se um protótipo, próximo ao LABEME/CT/UFPB, cujas paredes foram executadas com uso de blocos EVA, fabricados com traço 1:5 e $60 \%$ de EVA, substituindo agregados naturais, adotando-se os controles de produção (Quadro 1) para os blocos EVA, conforme Polari Filho (2005). Nesse protótipo foram realizados ensaios para verificar o desempenho das paredes ante cargas de ocupação e impactos.

Para a construção do protótipo foi necessária a confecção de cerca de 500 blocos EVA. Nesse processo, os blocos foram produzidos em escala laboratorial e, após a cura inicial em câmara úmida e os 7 dias subsequentes em cura por imersão em água e cal, foram estocados no ambiente externo ao LABEME/CT/UFPB. Para a construção do protótipo todos os blocos EVA tiveram idade superior a 28 dias. Esse protótipo representa um ambiente com pequenas dimensões $(3,14 \mathrm{~m}$ x 2,65 m) de uma edificação (Quadro 2).

\begin{tabular}{|c|c|}
\hline Blocos EVA & \\
\hline \multirow[b]{2}{*}{ Materiais } & $\begin{array}{l}\text { Traço de 1:5 (em volume), } 60 \% \text { de EVA e } 40 \% \text { de areia } \\
\text { Relação a/c }=0,56 \\
\text { Massa do bloco }=5,9 \mathrm{~kg}\end{array}$ \\
\hline & \\
\hline \multirow[t]{3}{*}{ EVA } & Dmáx $=9,5 \mathrm{~mm}$ \\
\hline & Massa Unitária $=248 \mathrm{~kg} / \mathrm{m}^{3}$ \\
\hline & Pré-molhagem do agregado EVA = $20 \mathrm{~min}$ \\
\hline \multirow[t]{3}{*}{ Areia } & Massa específica $=2.611 \mathrm{~kg} / \mathrm{m}^{3}$ \\
\hline & Massa unitária em estado solto $=1.634 \mathrm{~kg} / \mathrm{m}^{3}$ \\
\hline & Dmáx $=2,4 \mathrm{~mm}$ \\
\hline \multirow{3}{*}{$\begin{array}{r}\text { Cimento Portland } \\
\text { Água }\end{array}$} & CP II Z 32 RS \\
\hline & Potável proveniente do sistema de abastecimento da UFPB \\
\hline & Produção \\
\hline \multirow{5}{*}{ Parâmetro avaliado do bloco } & Mistura dos materiais em betoneira de $320 \mathrm{~L}$ \\
\hline & Moldagem dos blocos em máquina vibroprensa semiautomática \\
\hline & Cura dos blocos: câmara úmida + imersão em água saturada em cal \\
\hline & \\
\hline & Resistência à compressão média aos 28 dias igual a 1,2 MPa \\
\hline
\end{tabular}

Quadro 1 - Produção dos blocos EVA para construção do protótipo 


\begin{tabular}{|c|c|}
\hline Itens & Descrição/especificação \\
\hline Área construída & $8,32 \mathrm{~m}^{2}$ \\
\hline Pé-direito & $2,95 \mathrm{~m}$ \\
\hline $\begin{array}{r}\text { Alvenarias (espessura }=13 \\
\mathbf{c m})\end{array}$ & $\begin{array}{l}\text { Bloco EVA }(0,9 \mathrm{~cm} \times 0,19 \mathrm{~cm} \times 0,39 \mathrm{~cm}) \text { assentados com argamassa } \\
\text { no traço 1:2:10 (cimento:cal:areia) }\end{array}$ \\
\hline $\begin{array}{r}\text { Revestimento (espessura }=2,0 \\
\mathbf{c m})\end{array}$ & $\begin{array}{l}\text { Chapisco: traço 1:3 (cimento:areia) } \\
\text { Reboco: massa única com traço 1:2:10 (cimento:cal:areia) }\end{array}$ \\
\hline Coberta em duas águas & Madeiramento com telha canal cerâmica \\
\hline \multirow{5}{*}{$\begin{array}{r}\text { Verga/Contraverga } \\
\text { Cinta } \\
\text { Piso } \\
\text { Pintura }\end{array}$} & $\begin{array}{l}\text { Porta (folha prensada } 0,80 \mathrm{~m} \times 2,10 \mathrm{~m} \text {; forra com bandeira } 0,80 \mathrm{~m} \times \\
2,40 \mathrm{~m} \text { ) } \\
\text { Janela ( } 2 \text { folhas com } 0,50 \mathrm{~m} \times 0,90 \mathrm{~m} \text { e bandeira com } 1,00 \mathrm{~m} \times 0,30 \\
\text { Ferragem: fechadura, ferrolhos e dobradiças }\end{array}$ \\
\hline & Concreto armado nos vazios de blocos EVA (canaleta) \\
\hline & Concreto armado \\
\hline & Cimentado \\
\hline & $\begin{array}{l}\text { Cal nas paredes } \\
\text { Verniz nas esquadrias }\end{array}$ \\
\hline
\end{tabular}

Quadro 2 - Características do protótipo com blocos EVA

\section{Processo de construção do protótipo: alvenarias com blocos EVA}

No processo de construção do protótipo (Figura 2), foram utilizados blocos EVA com três dimensões diferentes $-9 \mathrm{~cm} \times 19 \mathrm{~cm} \times 19 \mathrm{~cm}$ (meio bloco), 9 cm x $29 \mathrm{~cm}$ x $19 \mathrm{~cm}$ (bloco especial) e $9 \mathrm{~cm}$ x 39 $\mathrm{cm} \times 19 \mathrm{~cm}$ (bloco inteiro) -, todos obtidos a partir de cortes feitos no bloco inteiro (Figura 3).

Durante a construção desse protótipo, em 2006, pôde-se verificar uma série de facilidades no uso dos blocos EVA para a execução das alvenarias, considerando-se a compatibilidade entre as dimensões dos blocos e a modulação do ambiente simulado no protótipo. De fato, foi notável também a facilidade na realização dos cortes dos blocos, sem quebras acidentais e com bom aproveitamento das partes, originando os outros elementos da família de blocos (meio bloco e bloco especial), e também permitindo a execução da parte do oitão do protótipo com os blocos EVA cortados. A utilização dos três tipos de blocos EVA (bloco inteiro, meio bloco e bloco especial) viabilizou a execução da alvenaria, garantido a amarração entre os elementos durante o assentamento das unidades. Também foi possível transformar alguns dos blocos EVA (inteiros) em canaletas para execução das vergas e da contraverga, no caso da janela (Figura 4). O processo de assentamento dos blocos foi simples e acelerado em função da redução de seu peso $(5,9$ $\mathrm{kg}$ ), comparativamente aos blocos de concreto simples.

A metodologia utilizada para avaliar as cargas, solicitações e impactos nas paredes do protótipo, construído com os blocos EVA, foi baseada nas normas NBR 8054 (ABNT, 1983), NBR 11678 (ABNT, 1990b) e NBR 11675 (ABNT, 1990a) e nas recomendações elaboradas para avaliação de desempenho de habitações térreas unifamiliares (IPT, 1981). 

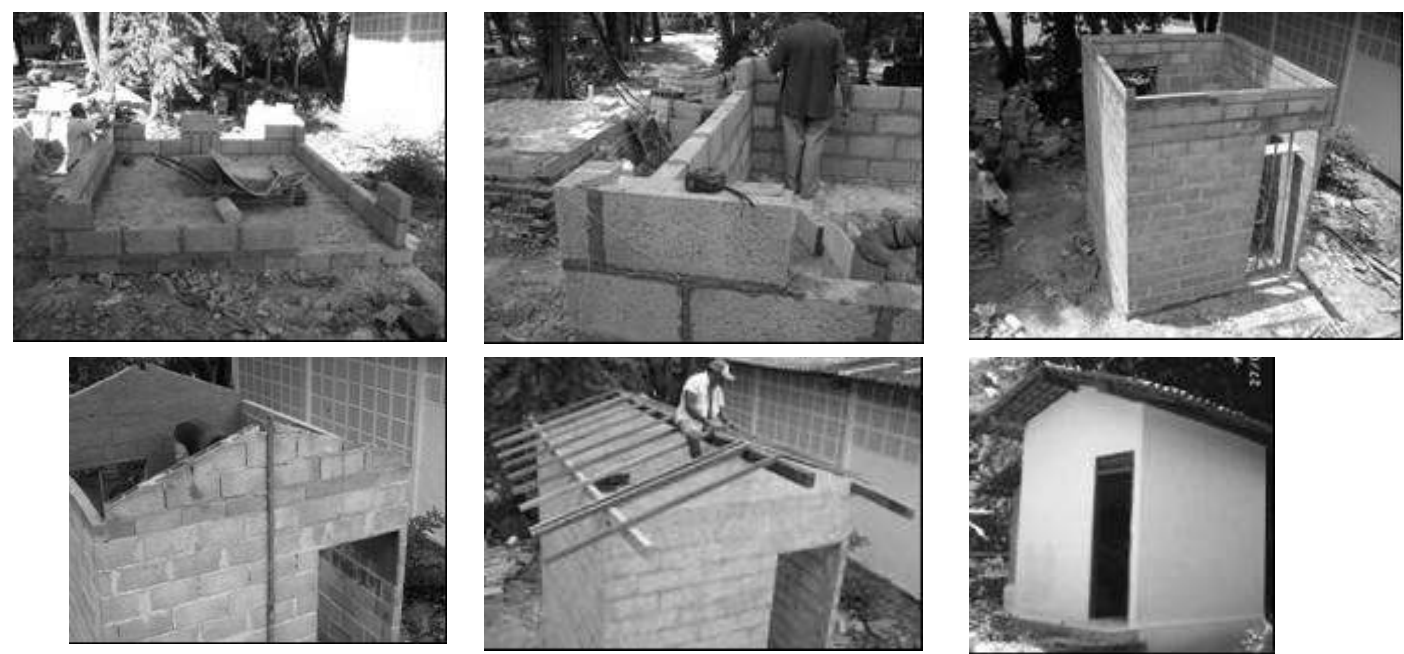

Figura 2 - Execução do protótipo com uso dos blocos EVA na área externa do LABEME/CT/UFPB
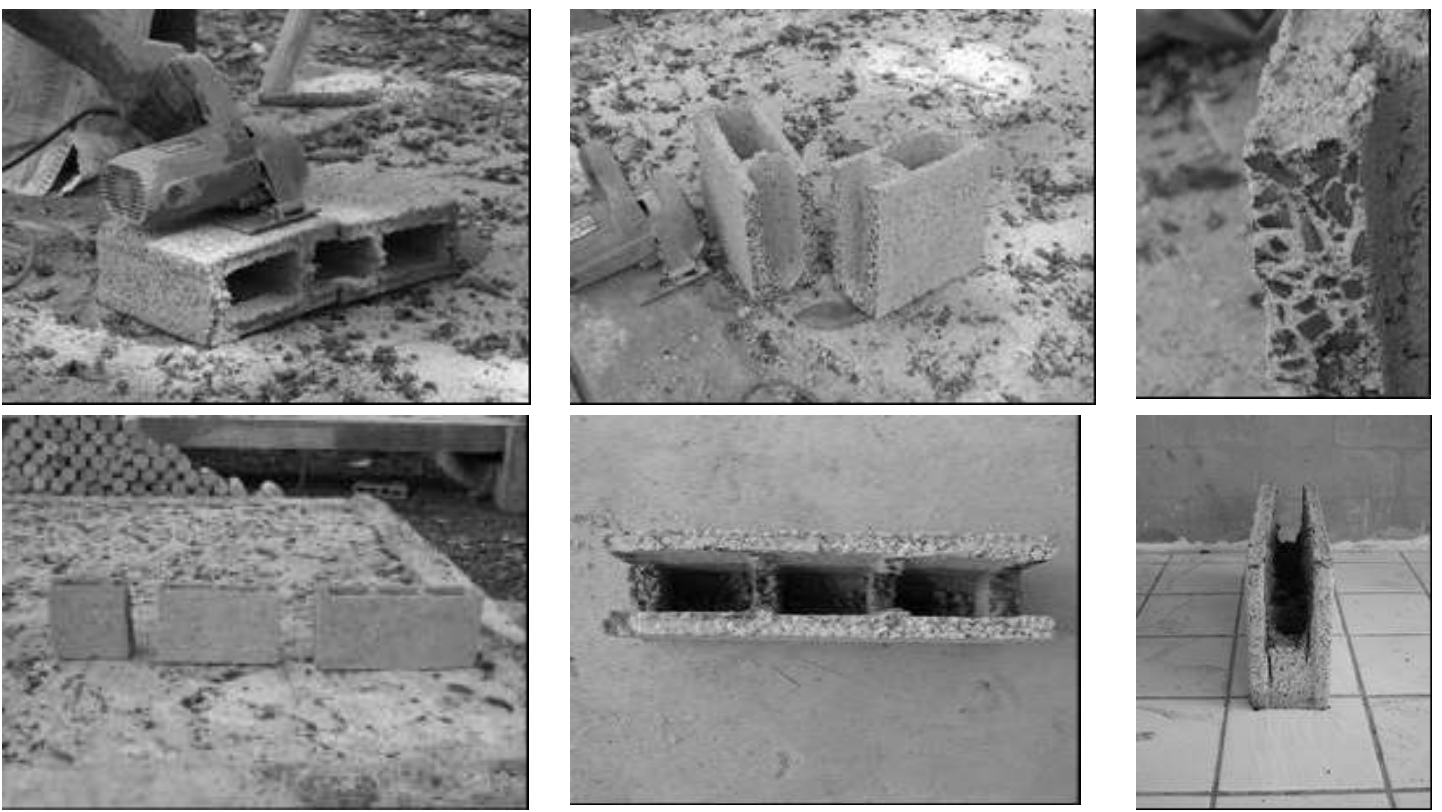

Figura 3 - Execução dos cortes nos blocos EVA para produzir os blocos da família e canaletas para vergas e contravergas 

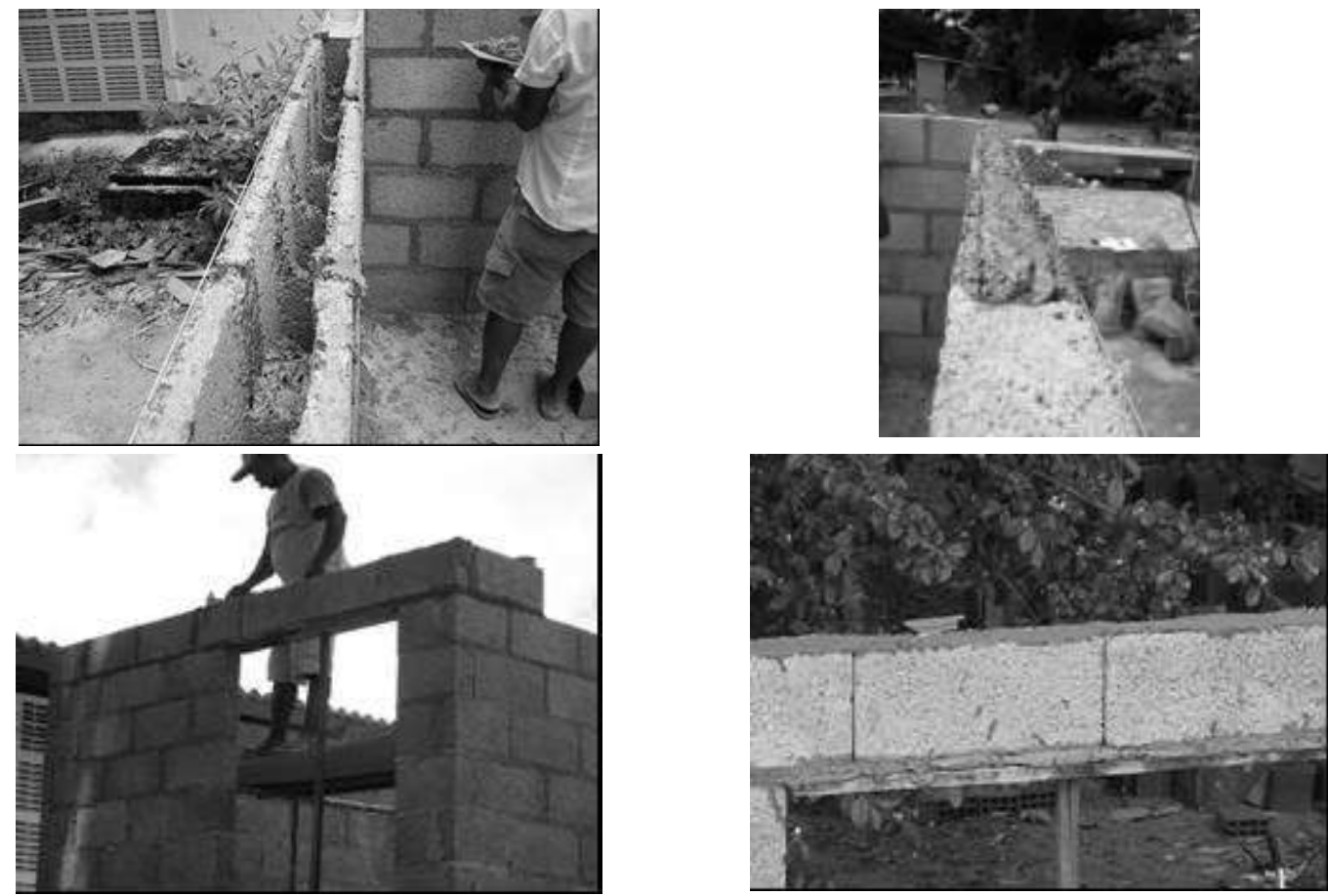

Figura 4 - Execução da verga e da contraverga com blocos EVA

\section{Ensaio de cargas provenientes de peças suspensas em paredes do protótipo}

No ensaio de cargas provenientes de peças suspensas em paredes a aparelhagem foi baseada na norma NBR 11678 (ABNT, 1990b), e a simulação foi reproduzida em duas paredes do protótipo por uma carga vertical excêntrica de 80 kgf. A aplicação da carga foi realizada mediante a fixação na parede do protótipo de uma peça suspensa padrão (mão-francesa). Após a fixação dessa peça, o ensaio iniciou-se com a colocação gradativa de pesos de $5 \mathrm{~kg}$ até atingir um total de $80 \mathrm{~kg}$, necessários para a simulação desejada, quando foram registradas as deformações, através de relógios comparadores fixados na face oposta da parede submetida à carga (Figura 5). A carga permaneceu aplicada por $24 \mathrm{~h} ; 15$ min após a retirada total da carga, as deformações residuais foram registradas.

Os elementos fixadores da peça padrão e a técnica de fixação utilizados neste ensaio foram bucha plástica comum IV-8, com perfuração da parede usando broca de referência 6,5 , e fixação da peça padrão com uso de parafuso. Para a transmissão da carga à parede na parte inferior do suporte (mãofrancesa) foram colocados dois discos de aço $(25$ $\mathrm{mm}$ de diâmetro e $10 \mathrm{~mm}$ de espessura). Esse local foi inspecionado visualmente após a retirada total da carga, para verificar se havia danos à parede.

De acordo com o ensaio realizado, o requisito é que as paredes devem apresentar resistência mecânica aos esforços produzidos por cargas provenientes de peças suspensas como armários, prateleiras, etc. Como critério de avaliação, as seguintes prescrições não podem ocorrer: deformações horizontais maiores que $\mathrm{h} / 500$; deformações horizontais residuais maiores que $\mathrm{h} / 2.000$, onde $\mathrm{h}$ é a altura do corpo de prova (parede); arrancamento dos fixadores ou elementos de fixação; rupturas, fissuras, escamações, nos locais de transferência das cargas (região de contato com os discos de aço) ou qualquer tipo de dano fora da região de aplicação da carga. É aceito na região de aplicação da carga o aparecimento de pequenas indentações ou amassamentos.

$\mathrm{O}$ resultado do ensaio com peças suspensas nas duas paredes do protótipo com blocos EVA confirmou o bom desempenho do material, considerando que os valores das deformações registradas foram muito pequenos e inferiores às deformações-limite e residuais (Tabela 1). Não ocorreu também arrancamento dos fixadores, nem quaisquer danos nas paredes ensaiadas. 

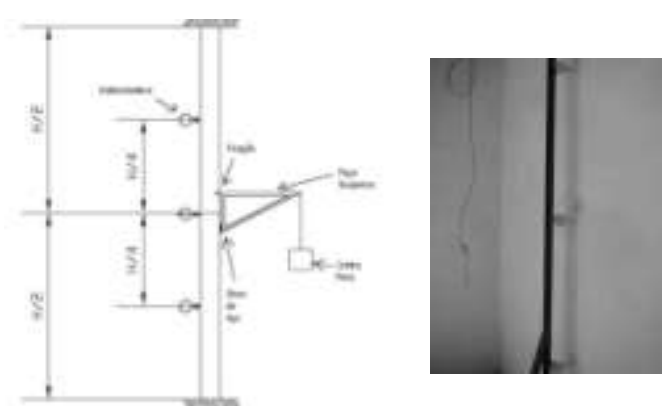

(a) Desenho esquemático da posição dos dispositivos e instalação dos relógios na face interna da parede
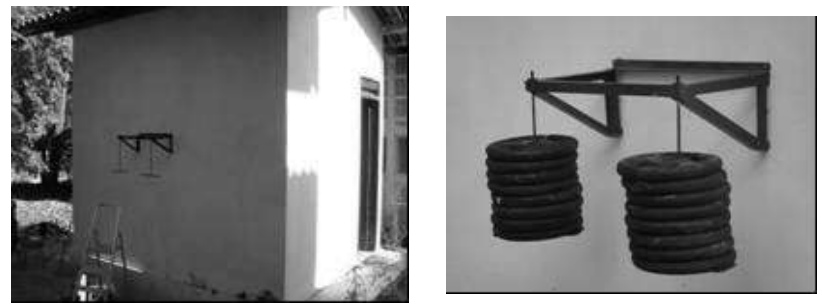

(b) Instalação de suporte (mão-francesa) e aplicação da carga na parede

Figura 5 - Ensaio de cargas provenientes de peças suspensas em parede do protótipo

\begin{tabular}{|c|c|c|c|}
\hline \multirow{2}{*}{$\begin{array}{c}\text { Parede Protótipo } \\
\mathbf{P 2} *(\mathbf{h}=2.950 \mathrm{~mm})\end{array}$} & \multicolumn{2}{|c|}{ Tipo de Fixação } & \\
\hline & Bucha: IV-8 & Broca: 6,5 & \\
\hline Deformações & Inicial (mm) & Final $(\mathrm{mm})$ & Residual (mm) \\
\hline ds & 0,000 & 0,020 & 0,020 \\
\hline dm & 0,000 & 0,040 & 0,046 \\
\hline di & 0,010 & 0,050 & 0,056 \\
\hline Deformação-limite & 5,900 & 5,900 & 1,475 \\
\hline \multicolumn{4}{|c|}{$\begin{array}{l}\text { *a outra parede apresentou valores muito semelhantes } \\
\text { Legenda: } \\
\text { h = altura da parede; } \\
\text { ds = deformação na parte superior; } \\
\text { dm = deformação na parte média; } \\
\text { di = deformação na parte inferior. }\end{array}$} \\
\hline $\begin{array}{l}\text { Tabela } 1 \text { - Deformações du } \\
\text { protótipo com bloco EVA }\end{array}$ & ensaio de carg & & la parede do \\
\hline
\end{tabular}

\section{Solicitações em paredes do protótipo por fechamento brusco de portas}

Neste ensaio verifica-se o comportamento da interface parede/porta devido a solicitações por manobras anormais como, por exemplo, batidas das portas devido à ação do vento. A aparelhagem do ensaio é baseada na norma NBR 8054 (ABNT, 1983). O procedimento consistiu em aplicar, perpendicularmente ao plano da porta, uma força de cerca de $15 \mathrm{kgf}$, para provocar seu fechamento. A folha, antes da aplicação da força, foi mantida aberta num ângulo de $60^{\circ}$ com o plano do batente (Figura 6a). Realizaram-se 10 fechamentos bruscos e, após cada um deles, foram inspecionadas a interface porta/parede e a porta isoladamente, para registro das ocorrências. O local de aplicação da força foi na maçaneta da própria porta, atendendo à condição de que deve ser em qualquer ponto situado a $1.000 \mathrm{~mm}$ do bordo inferior da folha e a $45 \mathrm{~mm}$ de seu bordo vertical.

A aparelhagem para aplicação da força foi constituída por um sistema composto de cabo de aço, roldanas e suporte para colocação de um contrapeso, de forma que fosse aplicada a força requerida (Figura 6b). O cabo de aço foi colocado de forma que, quando a porta chegasse a $3 \mathrm{~cm}$ de seu fechamento, a força aplicada não estivesse mais atuando.

$\mathrm{O}$ requisito e o critério são os de que as paredes não devem apresentar avarias graves nem rupturas submetidas a solicitações transmitidas por portas, como fissurações, destacamento no encontro com o marco, cisalhamento na região de solidarização do marco ou destacamento entre as juntas. O resultado desse ensaio foi considerado positivo, já que os 10 impactos produzidos não prejudicaram o funcionamento normal da porta, ou seja, não ocasionaram danos na folha, na forra e na parede. A pequena fissura que foi registrada na interface porta/parede, na verdade, já estava presente antes do início do ensaio, devido à movimentação diferenciada entre os materiais, por variação de temperatura e de umidade do ambiente. A abertura dessas fissuras permanece a mesma após o ensaio (Figura 6c). 


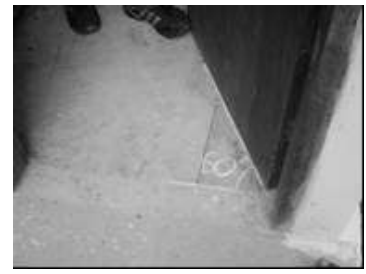

(a) Posicionamento da porta antes dos fechamentos

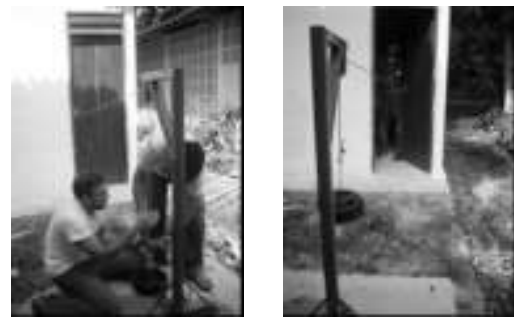

(b) Dispositivos utilizados durante o ensaio



(c) Pequena fissura na interface forra/parede já existente antes da realização do ensaio

Figura 6 - Realização do ensaio de fechamento brusco de porta

\section{Impactos de corpo duro e de corpo mole em paredes do protótipo}

Os ensaios para a avaliação dos impactos de corpo mole e de corpo duro foram baseados nos documentos do IPT (1981) e na NBR 11675 (ABNT, 1990a). Para a realização do ensaio de impactos de corpo duro em paredes do protótipo, utilizou-se a seguinte aparelhagem: uma esfera maciça de aço como corpo duro, com diâmetro aproximado de $500 \mathrm{~mm}$ e peso de $500 \mathrm{~g}$, e com diâmetro aproximado de $1.000 \mathrm{~mm}$ e peso de $1.000 \mathrm{~g}$; um sistema pendular constituído de um suporte com altura superior à altura da parede e um cabo de aço que foi destinado à sustentação da esfera maciça de aço; três relógios comparadores como dispositivos adotados para registro dos deslocamentos transversais da parede, instalados na face oposta aos impactos.

Os ensaios de corpo duro verificam o comportamento das paredes quando submetidas a choques gerados dentro da edificação, decorrentes de seu uso, ou externamente, através de corpo duro de pequena e grande dimensão. Esses impactos foram aplicados através de uma esfera maciça de aço abandonada em movimento pendular (Figura 7). Foram aplicados 10 impactos de cada modalidade (utilização e segurança), regularmente distribuídos pela superfície de duas paredes do protótipo. Para a realização desses impactos a esfera foi afastada da superfície da parede do protótipo, até que seu centro de massa atingisse as cotas relacionadas à energia necessária, como descrito na Tabela 2. Logo após a realização dos impactos na parede do protótipo, esta foi inspecionada visualmente, a fim de verificar as prescrições expostas na NBR 11675 (ABNT, 1990a).

Os requisitos são os de que, sob ação de impacto de corpo duro, as paredes não devem apresentar ruptura ou avarias graves que prejudiquem sua função ou aspecto. Os critérios são que nas paredes, quando sujeitas aos impactos de corpo duro de pequenas dimensões (esfera menor) aplicados em qualquer ponto, não devem ocorrer fissuras ou estilhaçamentos e mossas superiores a 2,0 $\mathrm{mm}$. Sob impactos de corpo duro de grandes dimensões (esfera maior) também aplicados em qualquer ponto da parede, não deve ocorrer ruptura ou traspassamento. O resultado desse ensaio mostrou que os poucos registros correspondem às mossas muitos superficiais no reboco (Figura 7b), o que significa bom desempenho.

Os ensaios de corpo mole visam verificar o comportamento de paredes quando submetidas a impactos decorrentes de choques acidentais provenientes do próprio uso da edificação ou choques provocados por tentativas de intrusões intencionais ou não. Para a realização desse ensaio, utilizou-se a seguinte aparelhagem (Figura 8), segundo a NBR 11675 (ABNT, 1990a): um saco cilíndrico de couro como corpo mole, com diâmetro e altura aproximada e respectivamente de $350 \mathrm{~mm}$ e $900 \mathrm{~mm}$, contendo no interior areia seca, com peso total de $40 \mathrm{~kg}$; um sistema pendular constituído de um suporte com altura superior à altura da parede e um cabo de aço, que foi destinado à sustentação do saco cilíndrico durante o ensaio; e três relógios comparadores colocados na face oposta da parede sob impacto, como dispositivo adotado para registro dos deslocamentos transversais da parede.

Durante o ensaio de corpo mole, o saco cilíndrico foi abandonado em movimento pendular, em direção ao centro da parede (Figura 8), sendo a altura da queda determinada de forma a produzir a energia de impacto de utilização e de segurança, conforme a Tabela 3, que é específicado para paredes externas com função estrutural. Durante a realização do primeiro impacto do corpo mole foi medida a deformação horizontal da parede, através das leituras dos relógios comparadores calibrados e ajustados.

Os requisitos são que, sob ação de impacto de corpo mole, as paredes externas devem apresentar resistência satisfatória, e suas deformações devem manter-se dentro dos limites aceitáveis. Os critérios estão relacionados às seguintes 
exigências: sob ação dos impactos de utilização com 120 J, 240 J, 360 J e 480 J, não devem ocorrer danos, ruptura ou instabilidade; sob ação dos impactos de segurança com $720 \mathrm{~J}$, não deve ter ocorrência de ruína; sob ação do primeiro impacto com energia de $240 \mathrm{~J}$, a deformação horizontal não deve ser maior que $\mathrm{h} / 250$, e a deformação horizontal residual, medida no terceiro impacto de $240 \mathrm{~J}$, não deve ser maior que $\mathrm{h} / 1.250$, sendo " $\mathrm{h}$ " a altura livre da parede. As ações de impactos de corpo mole nos elementos da edificação não devem também provocar danos a componentes, instalações e acabamentos acoplados ao elemento em análise. Os resultados obtidos com o protótipo com blocos EVA estão apresentados nas Tabelas 4 e 5 .

Como visto (Tabelas 4 e 5), no resultado de ensaio de corpo mole todos os valores de deformações, instantânea e residual, ficaram muito abaixo dos limites aceitáveis, atendendo-se a todos os critérios mínimos de segurança estrutural, o que implica um bom desempenho do protótipo com blocos EVA. Em todos os impactos não se registrou nenhuma ocorrência, inclusive nos locais críticos, tais como nas regiões próximas à janela (Figura 8c).
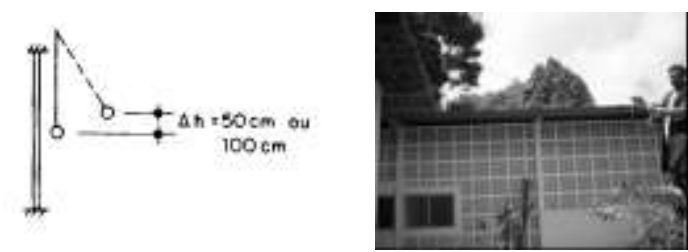


(a) Desenho esquemático e imagens durante o ensaio

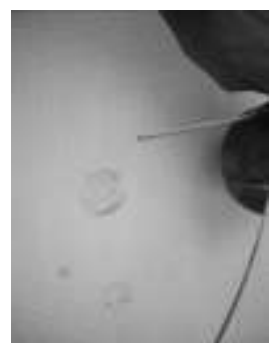

(b) Mossa no revestimento da parede após impacto

Figura 7 - Realização do ensaio de impacto de corpo duro no protótipo com bloco EVA

\begin{tabular}{|c|c|c|}
\hline Energia de imnacto (J) & $\begin{array}{c}\text { Utilização } \\
2,5\end{array}$ & $\begin{array}{c}\text { Segurança } \\
10\end{array}$ \\
\hline Massa da esfera (g) & 500 & 1.000 \\
\hline Altura de queda (cm) & 50 & 100 \\
\hline
\end{tabular}

Fonte: IPT (1981)

Tabela 2 - Relação entre a energia de impacto adquirida e a altura de queda da esfera



(a) Desenho esquemático

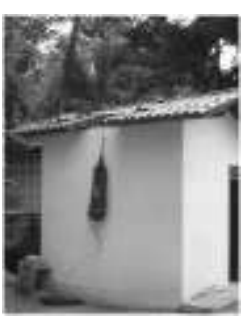

(b) Impacto na parede P02 (face sem aberturas)

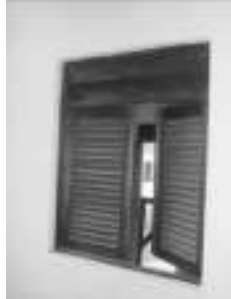

(c) Vista da janela (parede P03) sem nenhum dano após impactos

Figura 8 - Ensaio de impacto de corpo mole no protótipo com blocos EVA 


\begin{tabular}{|c|c|c|c|c|c|c|c|}
\hline \multirow[b]{2}{*}{ Sequência de impactos } & \multicolumn{4}{|c|}{ Impactos de utilização } & \multicolumn{3}{|c|}{ Impactos de } \\
\hline & $\mathbf{1}^{\mathbf{0}}$ & $\mathbf{2}^{\mathbf{o}}$ & $3^{\circ}$ & $4^{\circ}$ & $5^{\circ}$ & $6^{\mathbf{0}}$ & $7^{\circ}$ \\
\hline Energia de impacto $(\mathrm{J})$ & 120 & 240 & 240 & 240 & 360 & 480 & 720 \\
\hline Altura da queda $(\mathrm{cm})$ & 30 & 60 & 60 & 60 & 90 & 120 & 180 \\
\hline Exigências & \multicolumn{4}{|c|}{ nenhum dano } & \multicolumn{3}{|c|}{$\begin{array}{l}\text { admitidas fissuras, } \\
\text { escamações e outros }\end{array}$} \\
\hline
\end{tabular}

Tabela 3 - Relação da energia adquirida e da altura de queda do saco cilíndrico

\begin{tabular}{|c|c|c|c|c|c|c|}
\hline $\begin{array}{c}\text { Energia } \\
\text { (J) }\end{array}$ & $\begin{array}{c}\text { Deformação } \\
\text { instantânea } \\
(\mathbf{m m})\end{array}$ & $\begin{array}{c}\text { Deformação } \\
\text { residual } \\
(\mathbf{m m})\end{array}$ & Ocorrências & $\begin{array}{c}\text { Limite de } \\
\text { deformação } \\
\text { instantânea } \\
(\mathrm{mm})\end{array}$ & $\begin{array}{c}\text { Limite de } \\
\text { deformação } \\
\text { residual (mm) }\end{array}$ & \\
\hline 120 & 0,07 & 0,00 & Nenhuma & & \multirow[b]{4}{*}{2,36} & \multirow{4}{*}{$\begin{array}{l}\text { impactos } \\
\text { de } \\
\text { utilização }\end{array}$} \\
\hline 240 & 1,51 & 0,00 & Nenhuma & 11,80 & & \\
\hline 240 & 0,95 & 0,00 & Nenhuma & & & \\
\hline 240 & 0,96 & 0,00 & Nenhuma & & & \\
\hline 360 & 1,03 & 0,00 & Nenhuma & & & \multirow{3}{*}{$\begin{array}{c}\text { impactos } \\
\text { de } \\
\text { segurança }\end{array}$} \\
\hline 480 & 3,12 & 0,05 & Nenhuma & & & \\
\hline 720 & 3,00 & 0,13 & Nenhuma & & & \\
\hline
\end{tabular}

Tabela 4 - Resultado do ensaio de corpo mole na face externa da parede P03 (com janela) do protótipo com blocos EVA

\begin{tabular}{|c|c|c|c|c|c|c|}
\hline $\begin{array}{c}\text { Energia } \\
\text { (J) }\end{array}$ & $\begin{array}{c}\text { Deformação } \\
\text { instantânea } \\
(\mathrm{mm})\end{array}$ & $\begin{array}{c}\text { Deformação } \\
\text { residual } \\
(\mathbf{m m})\end{array}$ & Ocorrências & $\begin{array}{c}\text { Limite de } \\
\text { deformação } \\
\text { instantânea } \\
(\mathrm{mm})\end{array}$ & $\begin{array}{c}\text { Limite de } \\
\text { deformação } \\
\text { residual (mm) }\end{array}$ & \\
\hline 120 & 0,22 & 0,00 & Nenhuma & & \multirow[b]{4}{*}{2,36} & \multirow{4}{*}{$\begin{array}{l}\text { impactos } \\
\text { de } \\
\text { utilização }\end{array}$} \\
\hline 240 & 0,48 & 0,00 & Nenhuma & 11,80 & & \\
\hline 240 & 0,14 & 0,00 & Nenhuma & & & \\
\hline 240 & 0,34 & 0,00 & Nenhuma & & & \\
\hline 360 & 0,43 & 0,00 & Nenhuma & & & \multirow{3}{*}{$\begin{array}{c}\text { impactos } \\
\text { de } \\
\text { segurança }\end{array}$} \\
\hline 480 & 1,00 & 0,00 & Nenhuma & & & \\
\hline 720 & 1,71 & 0,00 & Nenhuma & & & \\
\hline
\end{tabular}

Tabela 5 - Resultado do ensaio de corpo mole na face externa da parede P02 (sem aberturas) do protótipo com blocos EVA

\section{Considerações finais}

A evolução dos estudos realizados nos últimos 10 anos para a produção de blocos EVA sem função estrutural é notável e, de certa maneira, oferece contribuições na avaliação de desempenho de materiais e componentes no processo de verificação necessária para a criação de novo produto, neste caso, o bloco EVA. Considerando o controle de variáveis de produção do bloco EVA (utilizado na construção do protótipo) e as limitações de sua moldagem em escala laboratorial (blocos com propriedades mecânicas aquém daquelas que um maquinário industrial pode lhes conferir), sugere-se como melhor resultado, até o momento, a adoção de traço 1:5 (em volume) com $60 \%$ de agregado EVA $\left(\mathrm{D}_{\text {máx }}=9,5 \mathrm{~mm}\right)$ e $40 \%$ de areia. A resistência à compressão média e a massa dos blocos assim produzidos foram 1,2 $\mathrm{MPa}$ e 5,9 $\mathrm{kg}$ respectivamente.

A construção do protótipo, em 2006, com paredes utilizando o bloco EVA (sem função estrutural) e as avaliações realizadas em 2007 (cargas de ocupação e impactos nas paredes) vieram contemplar uma importante etapa de estudo de verificação, no que se refere ao aspecto de segurança estrutural, considerando-o como parte dos critérios e requisitos para avaliação de desempenho da habitação. Portanto, a partir dos ensaios realizados neste protótipo destacam-se:

(a) bom desempenho das paredes submetidas às cargas provenientes de peças suspensas, com deformações muito inferiores aos valores-limite, com a ausência de arrancamento dos fixadores e quaisquer danos na parede; 
(b) resultado positivo pela ausência de danos na interface parede/porta devido às solicitações de fechamentos bruscos por manobras anormais;

(c) bom desempenho das paredes ante os choques decorrentes de impactos de corpo duro de pequena e grande dimensão, considerando-se os registros de mossas muitos superficiais no reboco; e

(d) bom desempenho das paredes quando submetidas a impactos (utilização e segurança) de corpo mole, considerando que todos os valores de deformações ficaram muito abaixo dos limites aceitáveis e pela ausência de danos nos componentes acoplados nas paredes (porta e janela).

Entende-se que ensaios de resistência à compressão de paredes e prismas devem ainda ser feitos, na próxima etapa da pesquisa, para comprovar a eficiência estrutural das paredes construídas com os blocos de EVA (traço 1:5) para a aplicação proposta no protótipo.

No processo de construção do protótipo várias facilidades foram destacadas com o uso dos blocos EVA, as quais são importantes na perspectiva da redução de resíduos de construção e demolição (RCD):

(a) a composição da família de blocos (meio bloco e bloco especial), para realizar as amarrações durante o assentamento das unidades na execução das alvenarias, foi facilmente obtida a partir de cortes feitos no bloco inteiro, com baixo desperdício de material;

(b) a obtenção de blocos do tipo canaletas (para execução das vergas e da contraverga) foi facilitada pela realização dos cortes das nervuras nos blocos inteiros; e

(c) o processo de assentamento dos blocos EVA foi simples e acelerado, em função da redução de seu peso $(5,9 \mathrm{~kg})$, comparativamente aos blocos de concreto simples.

O presente estudo oferece mais uma contribuição no processo evolutivo da pesquisa que visa ao aproveitamento dos resíduos de EVA na produção de blocos sem função estrutural, como uma alternativa válida na execução de alvenarias nos edifícios, indicando como válida a hipótese de resistência à compressão mínima igual a 1,2 MPa, como parâmetro de norma para o pré-moldado proposto. O valor de $1,2 \mathrm{MPa}$ sugerido como parâmetro aceitável para o bloco EVA leva em conta todo o conhecimento acumulado nas pesquisas sobre as propriedades e o comportamento do material, destacando-se os seguintes aspectos: (a) quando os valores das resistências à compressão dos blocos EVA foram maiores ou iguais a $1,2 \mathrm{MPa}$, o valor-limite para a propriedade absorção de água (Abs<10\%) sempre foi atendido (BEZERRA, 2002); e

(b) considerando a escala de experimentos realizados em laboratório, com controle de variáveis e com vários lotes de materiais (cimento Portland, areia e resíduos de EVA), constatou-se que a dosagem compatível com o menor consumo de cimento Portland (1:5), com a proporção ideal entre os agregados (40\% de areia e $60 \%$ de EVA) e com o menor beneficiamento do resíduo para produzir os agregados leves corresponde ao valor de 1,2 MPa de resistência à compressão para os blocos EVA.

As garantias de desempenho verificadas no protótipo sugerem um grande potencial de aplicação para o bloco EVA, com importantes repercussões na redução de impactos negativos no meio ambiente, na medida em que oferece uma alternativa ao destino para tais resíduos e uma redução do consumo de recursos naturais nas alvenarias dos edifícios.

Entretanto, há que se reconhecer a importância da continuidade na experimentação do novo material e componente propostos, tendo em conta outros critérios e requisitos de desempenho para habitação, tais como habitabilidade (conforto térmico e acústico, estanqueidade à água), durabilidade e a questão da segurança ao fogo.

\section{Referências}

ASSOCIAÇÃO BRASILEIRA DE NORMAS TÉCNICAS. NBR 11675 (MB 3256): divisórias leves internas moduladas: verificação da resistência a impactos. Rio de Janeiro, 1990.

\section{ASSOCIAÇÃO BRASILEIRA DE NORMAS} TÉCNICAS. NBR 11678 (MB 3259): divisórias leves internas moduladas: verificação do comportamento sob ação de cargas provenientes de peças suspensas. Rio de Janeiro, 1990.

\section{ASSOCIAÇÃO BRASILEIRA DE NORMAS TÉCNICAS. NBR 8054 (MB 1789): porta de madeira de edificação: verificação do comportamento da folha submetida a manobras anormais. Rio de Janeiro, 1983.}

\section{ASSOCIAÇÃO BRASILEIRA DE NORMAS TÉCNICAS. MB 3459: blocos vazados de} concreto simples para alvenaria: determinação da absorção de água, do teor de umidade e da área líquida. Rio de Janeiro, 1991. 
ASSOCIAÇÃO BRASILEIRA DE NORMAS

TÉCNICAS. NBR 7173: blocos vazados de concreto simples para alvenaria sem função estrutural. Rio de Janeiro, 1982.

BEZERRA, A. J. V. Utilização do Resíduo da Indústria de Calçados (EVA - Etileno Acetato de Vinila) como agregado Leve na Produção de Blocos Vazados de Concreto para Alvenaria sem Função Estrutural. 2002. Dissertação (Mestrado) - Curso de Ciência e Tecnologia, Universidade Federal da Paraíba, Campina Grande, 2002.

CALAES, Gilberto Dias et al. Bases para o Desenvolvimento Sustentável e Competitivo da Indústria de Agregados nas Regiões Metropolitanas do País: parte 1. Revista Escola de Minas, Ouro Preto, v. 60, n. 4, out./dez. 2007.

DE MELO, A. B.; SILVA, Helenir Vieira da. Avaliação de Alvenarias com Blocos de E.V.A. Executados em Protótipo em Escala Real: estudo de interações entre porta e peças suspensas com as alvenarias construídas com blocos de E.V.A. In: BEZERRA, Valdir Barbosa. (Org.). Série Iniciados. João Pessoa: Ed. Universitária/UFPB, 2007. v. 12 , p. $315-329$.

FERNANDES, Aldo Loy. Oferta e Demanda de Agregados para a Construçao Civil no Município de São Carlos, SP. 2007. Dissertação (Mestrado em Desenvolvimento Regional e Meio Ambiente) - Centro Universitário de Araraquara, Araraquara, 2007.
GARLET, G. Aproveitamento de Resíduos de E.V.A. (Ethylene Vinyl Acetate) como Agregado para Concreto Leve na Construção Civil. 1998. Dissertação (Mestrado em Engenharia Civil) - Escola de Engenharia, Universidade Federal do Rio Grande do Sul. Porto Alegre, 1998.

INSTITUTO DE PESQUISAS TECNOLÓGICAS DO ESTADO DE SÃO PAULO. Avaliação de Desempenho de Habitações Térreas

Unifamiliares: segurança estrutural. São Paulo: IPT, 1981.

JOHN, V. M. Reciclagem de Resíduos na Construção Civil: contribuição para metodologia de pesquisa e desenvolvimento. 113 f. 2000. Tese (Livre Docência) - Escola Politécnica, Universidade de São Paulo, São Paulo, 2000.

POLARI FILHO, R. S. Contribuição ao Processo de Reciclagem dos Resíduos da Indústria de Calçados na Construção Civil: bloco E.V.A.: uma alternativa às alvenarias das construções. Dissertação (Mestrado em Engenharia Urbana) Programa de Pós-Graduação em Engenharia Urbana, Universidade Federal da Paraíba, João Pessoa, 2005.

\section{Agradecimentos}

Ao LABEME/CT/UFPB, pelo apoio (pessoal e equipamentos) na concretização dos estudos; à Indústria de Calçados de João Pessoa, pela doação dos resíduos de EVA; e à FAPESQ/MCT/CNPq, pelo auxílio financeiro na execução de toda esta pesquisa. 